\title{
Cost-Benefit Analysis of Telemedicine Systems/Units in Greek Remote Areas
}

\author{
Marios-Nikolaos Kouskoukis ${ }^{1}$ - Charalambos Botsaris ${ }^{2}$
}

Published online: 14 November 2016

(c) The Author(s) 2016. This article is published with open access at Springerlink.com

\begin{abstract}
Background Telemedicine units and information technology systems provide special healthcare services to remote populations using telecommunication technology, in order to reduce or even remove the usual and typical face-to-face contact between doctor and patient. This innovative approach to medical care delivery has been expanding for several years and currently covers various medical specialties.

Objective To facilitate installation of telemedicine systems/units in Greek remote areas, this article presents results of a cost-benefit analysis for two Greek islands, Patmos and Leros, using specific economic criteria.

Methods Net present value (NPV), internal rate of return (IRR), and payback period were calculated, in order to monetize the economic benefits and the costs savings, estimate the depreciation of each project, and highlight the social benefits.

Results Costs were reduced (through saved air medical transportations) by $€ 19,005$ for Patmos and $€ 78,225$ for Leros each year. NPV and IRR were positive; NPV was $€ 29,608$ for Patmos and $€ 293,245$ for Leros, and IRR was $21.5 \%$ for Patmos and $140.5 \%$ for Leros. Each project
\end{abstract}

Marios-Nikolaos Kouskoukis

marioskousk@gmail.com

Charalambos Botsaris

botsaris@otenet.gr

1 Department of Economic and Regional Development, Panteion University of Political and Social Sciences, 42 Sofokleous Street, Voula, 16673 Athens, Greece

2 European Center for Interdisciplinary Research and Education, Panteion University of Political and Social Sciences, 136 Andrea Siggrou Avenue, Kallithea, 17671 Athens, Greece depreciated faster than the 5-year life-cycle period, and specifically in 3.13 years for Patmos and in 0.70 years for Leros.

Conclusion The establishment of telemedicine systems/ units in Patmos and Leros was evaluated and assessed positively, with large savings, economical and social, gained by reducing or even removing the face-to-face contact between doctor and patient. Telemedicine systems/ units seem to be a promising solution, especially in Greece, where the problem of primary healthcare services in remote/inaccessible areas is of great concern.

\section{Key Points for Decision Makers}

This study aimed to assess/evaluate the efficiency and efficacy of a telemedicine system/unit intervention, monetize the economic benefits, and conclude if it is desirable or not.

A larger population translates to a higher number of air medical transportations per year that can be avoided.

Telemedicine systems/units may have an advantage in terms of access, equality, and quality of primary health services.

\section{Introduction}

Telemedicine units exchange health data from one hospital or health center to another via electronic communications, providing real-time services to multiple healthcare centers regardless of their locations [1]. They have off-site 
command centers, usually in hospitals, where doctors and nurses are connected with distant patients through real-time audio, visual, and electronic means, enabling real-time monitoring of patient instability or any abnormality in the laboratory, ordering of diagnostics tests, diagnosis and treatment, and control of life-supporting devices [2].

A satisfying amount of research has been performed in the US and Europe, in order to examine the implementation and utilization of telemedicine systems/units to determine their efficiency and efficacy. The results concluded that current studies are early steps before telemedicine systems/ units become widespread, especially in Europe, implying that there is a lack of concrete evidence with which to fully assess the economic impact of telemedicine systems. Some cost-effectiveness analysis (CEA), cost-minimization analysis (CMA) and cost-utility analysis (CUA) studies demonstrated that telemedicine can reduce costs, but not all $[3,4,6]$. A CMA of telemedicine for two Greek islands was implemented, comparing the costs of telemedicine with those of referrals, where patients from remote areas travelled to the hospital for consultation, concluding that the costs of referrals were significantly greater than the costs of telemedicine [5].

Among the main limitations of the economic evaluations and assessments of telemedicine systems/units were the disparate estimation methods, a lack of randomized control trials, lack of long-term evaluation studies, small sample sizes, and absence of quality data and appropriate measures [6]. While many studies draw conclusions on cost based on decreased mortality and length of stay (LOS), actual cost was not reported [7-9].

Specifically, a review by the New England Healthcare Institute, the Massachusetts Technology Collaborative, and the Health Technology Center deduced that most (11 of 16) of the studies comparing similar intensive care units (ICUs) found a statistically significant decrease in hospital mortality, and most (11 of 15) also found a statistically significant decrease in ICU mortality. Similar to the findings of mortality rates, there was substantial evidence that 6 of 13 studies found a statistically significant decrease in hospital LOS and 11 of 17 found a significant decrease in ICU LOS [10]. Actual cost is a crucial factor that needs to be considered, especially for smaller facilities that pursue high return of investment (ROI), high net present value (NPV), high internal rate of return (IRR) and short payback period. NPV, ROI, IRR, and payback period are the economic criteria needed in order to assess and evaluate the project's efficiency and efficacy, monetize its economic benefits, and finally conclude if it is desirable or not [11-14].

The purpose of this study was to conduct a cost-benefit analysis of telemedicine systems/units in Greek remote areas with a case study of two Greek islands that have the same distance to air medical transportation centers in Athens and Rhodes, in order evaluate, assess, and compare the costs and potential financial benefits through the NPV, IRR, and payback period economic criteria, so that regional health disparities could be obviated.

\section{Methods}

The method employed for this cost-benefit study is based on three economic criteria: NPV, IRR, and payback period (Table 1). NPV is a measure of profitability and it is used to assess a given project's potential ROI. A positive NPV indicates that the projected earnings generated by the project or investment exceed the anticipated costs. A project with positive NPV will be profitable, while a project with negative NPV will result in net loss. The criterion of IRR is the interest rate, also called discount rate, that is required to bring NPV to zero. It should also be positive and is directly dependent on NPV. The higher the project's IRR, the more desirable it is to be implemented. The project with the highest IRR would probably be considered the best and undertaken first. The payback period indicates the number of years a project or investment needs in order to be depreciated. It should be as close as it can be to 0 , in order to depreciate the investment as fast as possible. The project with the lowest payback period would probably be considered better investment [11-14].

The two islands studied were Leros and Patmos, and the distance of each one of them from the air medical transportation centers in Athens and Rhodes was approximately equal. Leros has a slight advantage when the air medical transportation is to Rhodes and Patmos has the advantage when the air medical transportation is to Athens. From January 2005 till December 2014, 304 air medical transportations were completed from the two island of the Aegean to the air medical transportation centers [15]. Therefore, there was an average of 30.4 air medical transportations per year, taking into account a period of 10 years.

Leros, according to the latest statistical data (2011 census), has 7917 residents, and the distance from the two air medical transportation centers, Athens and Rhodes, is 331 and $182 \mathrm{~km}$, respectively. Specifically, from the average 30.4 air medical transportations per year, calculation of air medical transportations per year for Leros based on population is 21.95 (average air medical transportations per year multiplied by the Leros population and divided by the total population of the two islands).

Patmos has 3047 residents (2011 census) and the distance from the two air medical transportation centers, Athens and Rhodes, is 305 and $216 \mathrm{~km}$ respectively. From the total 30.4 air medical transportations per year, 
Table 1 Economic criteria

\begin{tabular}{ll}
\hline Economic criteria & Formula \\
\hline Net present value & $\Sigma\left\{\right.$ Period net cash inflows $\left./(1+r)^{\wedge} t\right\}-$ initial investment \\
Internal rate of return & $\Sigma\left\{\right.$ Period net cash inflows $\left./(1+r)^{\wedge} t\right\}-$ initial investment $=0$ \\
Payback period & $n_{\mathrm{y}}+n / p$ \\
\hline
\end{tabular}

$n$ The absolute value of cumulative net cash inflow at which the last negative value of cumulative net cash inflow occurs, $n_{y}$ the number of years after the initial investment at which the last negative value of cumulative net cash inflow occurs, $p$ the value of net cash inflow at which positive value of cumulative net cash inflow occurs, $r$ discount rate, $t$ number of time periods

Table 2 Economic parameters for Leros and Patmos

\begin{tabular}{lll}
\hline Economic parameters & Patmos & Leros \\
\hline Initial project costs & $€ 55,000$ & $€ 55,000$ \\
Operation costs/year & $€ 18,000$ & $€ 18,000$ \\
Average air transportation costs & $€ 5846$ & $€ 5846$ \\
Life cycle of project & 5 years & 5 years \\
Discount rate & $4 \%$ & $4 \%$ \\
Cash inflows/year & $€ 37,005$ & $€ 96,225$ \\
Net cash inflows/year & $€ 19,005$ & $€ 78,225$ \\
\hline
\end{tabular}

calculation of air medical transportations per year for Patmos based on population is 8.44 (average air medical transportations per year multiplied by Patmos population and divided by the total population of the two islands).

In order to fulfill the economic evaluation and assessment of telemedicine systems/units for the two islands, the following data from the Greek Ministry of Health and Military Airforce were used as fixed (year 2014 costs) (Table 2):

(a) Initial costs of a telemedicine system/unit were $€ 55,000$. These costs include the cost of acquiring the appropriate telemedicine equipment, the cost of transporting and installing it, and the training cost of medical personnel/human resources. The equipment of a telemedicine system/unit consists of IT equipment (hardware and software), office equipment, the access control system, and medical equipment (high resolution camera for macroscopic examination, digital stethoscope, rinoscope, otoscope, 12-lead cardiograph, ophthalmoscope, dermatoscope, and vital signs monitor) [16].

(b) Operating costs of a telemedicine system/unit were $€ 1500$ per month. These costs include the total cost of the salary of one employee, who is responsible for the proper functioning of a telemedicine system/unit and the maintenance costs of the equipment [16].

(c) Average air transportation costs (average air transportation costs of each trip) were $€ 5846$ for Super Puma helicopters, which were mostly used. The cost of each
Table 3 Economic criteria for Patmos and Leros

\begin{tabular}{lll}
\hline Economic criteria & Patmos & Leros \\
\hline Net present value & $€ 29,608$ & $€ 293,245$ \\
Internal rate of return & $21.5 \%$ & $140.5 \%$ \\
Payback period & 3.13 years & 0.70 years \\
\hline
\end{tabular}

air transportation depends on various facts, such as the distance and means of air transportation [15].

(d) The life cycle of a telemedicine system/unit installation was 5 years.

(e) Discount rate was $4 \%$, representing the average return on deposits' interest.

\section{Results}

Based on statistical data, air medical transportations cannot be avoided completely [15]. Approximately 25\% of cases demand air transportation to a hospital. As a result, from the 21.95 air medical transportations from Leros per year, 16.46 can be avoided, while from the 8.44 air medical transportations per year from Patmos, 6.33 can be avoided. Specifically, from 21.95 and 8.44 air medical transportations, only $25 \%$ of them (5.49 and 2.11 , respectively) should be authorized.

Taking into account the saved costs from the installation of a telemedicine system/unit, the net cash inflows per year (cash inflows per year minus operation costs per year) were amplified during the 5-year period of the project. Patmos cash inflows per year were the multiplying result of 6.33 air medical transportations saved per year due to the implementation of telemedicine system/unit, with the average air transportation costs per trip. For Leros, were the multiplying result of 16.46 air medical transportations saved per year due to the implementation of telemedicine system/unit, with the average air transportation costs per trip. This resulted in higher NPV and IRR. Moreover, the payback period reached low levels in both islands due to faster depreciation of the investment.

Interpreting the results of Table 3, we can see that there is a positive evaluation and assessment of the 
implementation of a telemedicine system/unit in both islands. NPV is positive for both Patmos $(€ 29,608)$ and Leros (€293,245), demonstrating that both telemedicine systems/units can be installed. IRR is also positive due to the above criterion; specifically $21.5 \%$ for Patmos and $140.5 \%$ for Leros. The payback period is lower than the life cycle of each project, which means that the implementation of a telemedicine system/unit will be depreciated before the 5-year period in both islands; specifically, 3.13 years for Patmos and 0.70 years for Leros $[15,16]$.

\section{Discussion}

Few economic evaluations of telemedicine can be trusted to provide reliable information for decision making. The majority of the assessments were not in accordance with standard evaluation techniques and still have a long way to go before governments or private investors can rely on them to produce valid and solid cost-effectiveness, costbenefit, cost-minimization and cost-utility data [8-11]. Some of them demonstrated that the costs can be reduced, providing higher quality of health services, while some of them reached the conclusion that costs cannot be minimized with quality of health services unchanged. The reason is that each case study is different, depending on a variety of factors such as the infrastructure, size and location of each hospital, the organizational structures, the condition of patients, the type of telemedicine system/unit, and how it is used $[4,6,7,12]$.

The main methodological similarities between these economic evaluations and assessments were the two rates that were used for the measurement of cost, the mortality and LOS rate. The purpose was to compare the costs of these rates before and after the intervention of telemedicine systems/units and conclude if they were decreased or not. Some of them tried to calculate the ROI, NPV, and payback period economic criteria, but in a cost-based method, having in mind the net savings from the use of telemedicine systems/units and ignoring factors that are crucial and important for the calculation of these criteria, such as the discount rate and the life cycle of the project [11, 12].

The main contribution of this original research, having in mind these economic evaluations and assessments, is to go one step further and calculate the NPV, ROI, IRR, and payback period economic criteria, in order to assess and evaluate the efficiency and efficacy of a telemedicine system/unit intervention, and monetize the economic benefits, concluding if it is desirable or not (from both economical and social perspectives).

Some of the main limitations and weaknesses of the economic evaluation and assessment of telemedicine systems/units in Greek remote areas can be the lack of interested doctors, absence of funding or subsidizing of the project by the government, local treatment procedures, and organizational structures. These limitations and weaknesses can affect the validity of the results by canceling the whole project or increasing or decreasing the costs.

Considering the results, a telemedicine system/unit installation on Leros seems to be more desirable due to a larger population, which indicates that the saved costs will be higher than on Patmos. A larger population translates to a higher number of air medical transportations per year that can be avoided. Specifically, the net cash inflows for Leros during the 5-year period are 4.12 times higher than for Patmos (Table 2). As a result, Leros will depreciate the investment in 0.70 years, while Patmos will take 3.13 years (Table 3 ).

Furthermore, the implementation of telemedicine systems/units may have some positive aspects, which may lead to the obviation of regional health disparities and create a sense of security for both patients and doctors, thus providing decent primary healthcare services to the residents of such remote/inaccessible areas.

The installation of a telemedicine system/unit in a remote/inaccessible area aims to cover both emergency situations and some of the regular needs of each island on a healthcare level. It also aims to improve patients' healthcare until their transfer to a hospital, but also the preparation of the doctors at the air medical transportation center.

Summarizing, telemedicine systems/units are estimated to result in a significant reduction in the number and frequency of air medical transportations, which may consequently lead to the reduction of aviation accidents that may occur during the air medical transfer. Despite the potential advantage of a reduction in human lives lost, medical and technical equipment losses are also of great significance.

The establishment of such telemedicine systems/units also enables patient and healthcare issues to be handled in the event of severe weather phenomena, where the remote/ inaccessible areas are isolated with no accessibility by any means.

\section{Conclusion}

Greece's geography encompasses a total of 227 inhabited islands, 164 of which are located in the Aegean Sea and 78 of them have more than 100 residents. The incomplete coverage of primary health services in remote/inaccessible areas, combined with Greece's unique geography, suggests the need for telemedicine systems/units.

Telemedicine systems/units should be designed and implemented in such way as to meet the primary health needs of every resident, in every island or remote/inaccessible area. However, air medical transportation of 
patients to air medical transportation centers may be deemed essential. The costs of these air medical transfers can be reduced with the use of telemedicine systems/units, thereby benefiting the residents and society generally.

In conclusion, considering the available data, in both projects, the establishment of telemedicine systems/units in Patmos and Leros was evaluated and assessed positively, with the possibility of large savings, both economical and social, by reducing or even removing face-to-face contact between doctor and patient. Telemedicine systems/units may have an advantage in terms of access, equality, and quality of primary health services and seems to be a promising solution, especially in Greece, where the problem of primary healthcare services in remote/inaccessible areas is of great concern.

Author contributions The paper was conceived by MK and CB. MK contributed the study design, collection of data, statistical analysis and writing of the manuscript. CB commented on initial drafts of the manuscript and approved the final version.

Data availability statement The data that support the findings of this study are available from the corresponding author on request.

\section{Compliance with Ethical Standards}

No funding was received during the implementation of this study. Marios-Nikolaos Kouskoukis has no conflicts of interest to declare. Charalambos Botsaris has no conflicts of interest to declare.

Open Access This article is distributed under the terms of the Creative Commons Attribution-NonCommercial 4.0 International License (http://creativecommons.org/licenses/by-nc/4.0/), which permits any noncommercial use, distribution, and reproduction in any medium, provided you give appropriate credit to the original author(s) and the source, provide a link to the Creative Commons license, and indicate if changes were made.

\section{References}

1. Rosenfeld BA, Dorman T, Breslow MJ, Pronovost P, Jenckes M, Zhang N. Intensive care unit telemedicine: alternate paradigm for providing continuous intensivist care. Crit Care Med. 2000;28(12):3925-31.

2. Stafford TB, Myers MA, Young A, Foster JG, Huber JT. Working in an eICU unit: life in the box. Crit Care Nurs Clin N Am. 2008;20(4):441-50.

3. Davalos ME, French MT, Burdick AE, Simmons SC. Economic evaluation of telemedicine: review of the literature and research guidelines for benefit-cost analysis. Telemed e-Health. 2009;15(10):933-48.

4. Wade VA, Karnon J, Elshaug AG, Hiller JE. A systematic review of economic analyses of telehealth services using real time video communication. BMC Health Serv Res. 2010;10:233.

5. Tsitlakidis C, Mylonakis J, Niakas D. Economic evaluation of telemedicine for a remotely located population: the case of two Greek islands. Int J Electron Healthc. 2005;1(3):243-60.

6. De La Torre-Diez I, Lopez-Coronado M, Vaca C, Aguado JS, De Castro C. Cost-utility and cost-effectiveness studies of telemedicine, electronic, and mobile health systems in the literature: a systematic review. Telemed J E-Health. 2015;21(2):81-5.

7. Thomas EJ, Lucke JF, Wueste L, Weavind L, Patel B. Association of telemedicine for remote monitoring of intensive care patients with mortality, complications and length of stay. J Am Med Assoc. 2009;302(24):2671-8.

8. Cummings J, Krsek C, Vermoch K, Matuszewski K. Intensive care unit telemedicine: review and consensus recommendations. Am J Med Qual. 2007;22(4):239-50.

9. Breslow MJ, Rosenfeld BA, Doerfler M, Burke G, Yates G, Stone DJ, Tomaszewicz P, Hochman R, Plocher DW. Effect of a multiple-site intensive care unit telemedicine Program on clinical and economic outcomes: an alternative paradigm for intensivist staffing. Crit Care Med. 2004;32(1):31-8.

10. New England Healthcare Institute, Massachusetts Technology Collaborative, Health Technology Center. Tele-ICUs: Remote management in intensive care units. In: Publications. Network for Excellence in Health Innovation. 2007. http://www.nehi.net/ writable/publication_files/file/tele_icu_final.pdf. Accessed 1 Mar 2007.

11. Kumar S, Merchant S, Reynolds R. Tele-ICU: efficacy and costeffectiveness approach of remotely managing the critical care. Open Med Inform J. 2013;7:24-9.

12. Coustasse A, Deslich S, Bailey D, Hairston A, Paul D. A business case for tele-intensive care units. Perm J. 2014;18(4):76-84.

13. Readon $\mathrm{T}$. Research findings and strategies for assessing telemedicine costs. Telemed J E-Health. 2005;11(3):348-69.

14. Broomhead S, Mars M. Retrospective return on investment analysis of an electronic treatment adherence device piloted in the Northern Cape Province. Telemed J E-Health. 2012;18(1):24-31.

15. Greek Military Airforce-Statistical Data 2005-2014.

16. Ministry of Health-Statistical Data 2016. 